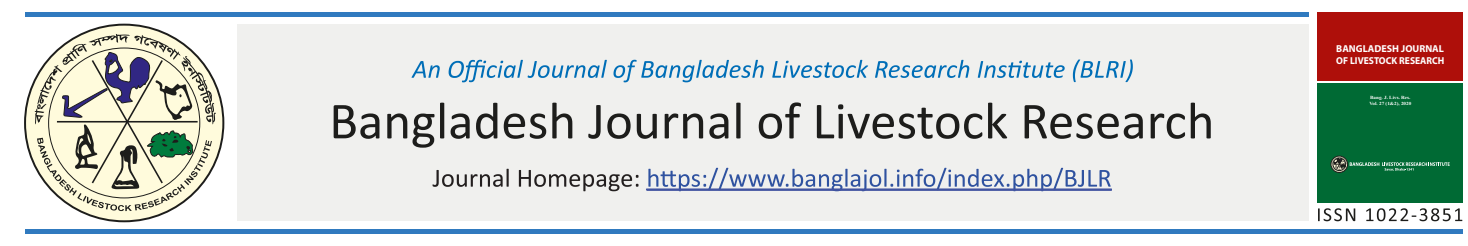

\title{
Isolation, identification and biochemical characterization of lactic acid bacteria from selected yogurt samples
}
S. M. Amanullah ${ }^{1 *}$, M. A. Kabir ${ }^{1 \dagger}$, M. M. Rahman ${ }^{1}$, P. Halder ${ }^{2}$, S. M. J. Hossain ${ }^{1}$ and M. A. Samad $^{3}$
${ }^{1}$ Biotechnology Division, Bangladesh Livestock Research Institute, Savar, Dhaka;
${ }^{2}$ Department of Biochemistry and Molecular Biology, Jahangirnagar University, Dhaka;
${ }^{3}$ Animal Health Research Division, Bangladesh Livestock Research Institute, Savar, Dhaka
${ }^{\dagger}$ MA Kabir contributed equally as the first author

\begin{abstract}
This research was conducted to study the types of lactic acid bacteria (LAB) present in selected yogurts available in the local market of Bangladesh. For this purpose, nine different yogurt samples were collected (viz. MV, Mw, Pst, Psr, Bik, Bog, WF, Kw and Nab) and cultured in the selective MRS agar media for enumerating LAB colony. Out of 9 samples, colony forming LAB were found in 6 samples and the population ranged from $1.0 \times 10^{4}$ to $9.5 \times 10^{5} \mathrm{cfu} / \mathrm{ml}$. Catalase negative and Gram's positive colonies were initially identified as LAB. Then the isolates were purified by subsequent culturing in MRS broth and MRS agar media. Biochemical properties of selected colonies were evaluated by performing gas production from glucose, growth at different temperatures $\left(10^{\circ} \mathrm{C}, 15^{\circ} \mathrm{C}\right.$ and $\left.45^{\circ} \mathrm{C}\right)$, growth at different $\mathrm{NaCl}$ concentrations $(2,4$ and $6.5 \% \mathrm{NaCl})$ and sugar fermentation tests (lactose, sorbitol, salicin, trehalose, melibiose, sucrose, mannitol, melezitose, maltose, galactose, glucose, arabinose, raffinose and ribose). According to the tests stated above, a total of five different species of LAB were identified from 6 samples. The isolate Lactobacillus lactis was identified in MV, PSr and Bog yogurt, while Lactobacillus bulgaricus was found in MV and Bik yogurt. The species Leuconostoc cremoris, a avor producing bacteria, was found in six yogurt samples. On the other hand, Lactobacillus acidophilus and Lactobacillus helveticus was found only in Pst and Psr samples, respectively.
\end{abstract}

Key words: Yogurt, lactic acid bacteria, biochemical characterization.

Bang. J. Livs. Res. Vol. 27 (1\&2), 2020: P. 64-72. $\quad$ https://doi.org/10.3329/bjlr.v27i1.55170

\section{Introduction}

Yogurt is a food obtained by control fermentation of milk by selective culture of lactic acid bacteria (LAB) being imparted

*Corresponding author: amanullah@blri.gov.bd 
flavor and typical aroma compound. It is easily digested and vital for health because of its high protein and fat content, lactose, minerals specially calcium and phosphorous, important vitamins and lactic acid (Ali et al., 2002). Yogurts may provide additional health benefits, for example it may reduce cholesterol levels and certain diseases with gastrointestinal tract such as lactose intolerance, diarrhea, colon cancer and other bacterial infection are inhibited through high consumption of yogurt (Hossain et al., 2015). Usually quality of yogurt depends on quality of starter culture. According to Food and Drug administration Streptococcus thermophilus and Lactobacillus bulgaricus is obligatory for yogurt starter culture but they also suggested some additional bacteria viz. Lactobacillus acidophilus, Lactobacillus casei, Lactobacillus helveticus, Lactobacillus jugurti, Lactobacillus lactis, Bifidobacterium longum, Bifidobacterium bifidum and Bifidobacterium infantis to use as starter culture bacteria (Hui, 1992).

In Bangladesh, traditionally yogurt is produced both in household and commercially for selling at market. The Starter culture used to produce these yogurt or types of microbes available in those marketed yogurt is not studied well. In some cases, microbial quality of yogurt in Bangladesh was not found satisfactory due to adulteration and poor hygienic condition of shops (Hassan et al.,2016). Moreover, shop keepers in urban areas usually preserve yogurt in freezer, which may hamper the viability of LAB in yogurt. As a result, the consumer may be depriving from obtaining desired LAB through yogurt. The present study would be able to provide information on the contents of LAB in some available yogurt samples. This may help to create consumer's awareness, using suitable starter bacteria and adoption of proper storage management from factory to retailer by the manufacturer and formulation of regulations for ensuring yogurt quality in terms of microbial contents.

\section{Materials and Methods}

\section{Time and place of the Experiment}

The present experiment was conducted at the Biotechnology Division of Bangladesh Livestock Research Institute (BLRI), Savar, Dhaka-1341, from April 2017 to November 2018.

\section{Sample Collection}

Nine marketed yoghurt samples by different producers were collected from local market at Savar, Dhaka. These were MV, Mw, Pst, Psr, Bik, Bog, WF, Kw and Nab yogurt. Immediately after collection, samples were transferred at low temperature (using ice-box) to the laboratory. The pour-plate method was conducted immediately on the same day for LAB enumeration, colony morphology and isolation.

\section{Enumeration of LAB}

The enumerations of live colonies of LAB in the collected samples were performed by culturing bacteria on MRS agar media. Briefly, samples were homogenized and 3 $\mathrm{ml}$ of each sample was poured into a screw-cap tube containing $27 \mathrm{ml}$ of $0.85 \%$ $\mathrm{NaCl}$ solution and vortexed to mix thoroughly. Considering this as the first dilution, ten-fold serial dilution was made. Hundred microliter $(0.1 \mathrm{ml})$ aliquots from subsequent two dilutions $\left(10^{-4}\right.$ and $10^{-5}$ 
dilutions) were poured on MRS agar media in two replicates. Inoculated plates were then incubated at $37^{\circ} \mathrm{C}$ for 48 hours in an incubator (Daihan, WIG-50, and Korea). After 48 h, visible colonies were counted from the plates at appropriate dilutions and the number of colony-forming units (cfu) was expressed per $\mathrm{ml}$ of sample.

\section{Isolation and purification of $\mathrm{LAB}$ isolates}

Isolation of bacteria was performed by pour plating technique using MRS agar media. This was done simultaneously during the step of enumeration. Initial identification was performed based on Gram's Staining and catalase test following the procedure described by Sharpe (1979). The colonies which were found white in color, Gram-positive and catalase-negative were considered as LAB (Sharpe, 1979). Then the LAB isolates were purified by culturing in MRS broth and MRS agar media sequentially until similar colonies were found. Finally, the purified isolates were identified by performing different biochemical tests.

\section{Gram staining}

Morphological status of isolated bacteria was determined using Gram staining. One $\mathrm{ml}$ of overnight activated broth culture was aliquoted into an Eppendorf tube and centrifuged at $6000 \mathrm{rpm}$ for $5 \mathrm{~min}$. The supernatant was removed and cells were re-suspended in sterile saline water. Ten microliters of cell suspension were pipetted to a microscopic slide and they were Gram-stained after drying and fixation by exposure to a flame. Briefly, staining was performed with crystal violet solution for 1 minutes as first step, followed by washing with tap water. Then iodine solution was placed on slide and kept for 1 minute followed by washing under tap water. Then 95\% ethanol was used for 15 seconds until violet stain was removed from the slide. After removing ethanol by washing under tap water, slide was counterstained with safranine for 30 seconds. Finally, the slide was washed again under tap water and dried by using blot paper and observed under a microscope using 20x magnifications. Gram-positive organisms stained blue-purple, while, gram-negatives became pink-red after Gram staining (Erkuş, 2007).

\section{Catalase test}

Catalase enzyme breaks down hydrogen peroxide $\left(\mathrm{H}_{2} \mathrm{O}_{2}\right)$ into oxygen and water molecules $\left(2 \mathrm{H}_{2} \mathrm{O}_{2} 2 \mathrm{H}_{2} \mathrm{O}+\mathrm{O}_{2}\right)$ and oxygen production is observed by the generation of $\mathrm{O}_{2}$ bubbles. The generation of gas bubbles indicates presence of the enzyme, hence the catalase positive nature of the bacterium. A sterile loop was used to transfer a small amount of colony on the surface of a clean, dry glass slide. A drop of $3 \% \mathrm{H}_{2} \mathrm{O}_{2}$ was placed right over the colony and observed for the evolution of oxygen bubbles (Reiner, 2010).

\section{Gas production from glucose}

Carbon di-oxide production from glucose is the major criterion for the determination of homofermentative or heterofermentative nature of an isolate. MRS broths containing inverted Durham tubes were utilized to determine $\mathrm{CO} 2$ production. Fifty micro litres of overnight activated cultures were inoculated into $8 \mathrm{ml}$ MRS broth containing inverted Durham tubes in triplicates and incubated for 5 days at $37^{\circ} \mathrm{C}$. The $\mathrm{CO}_{2}$ production 
was observed as an accumulation of gas in the inverted tubes.

\section{Growth at different temperatures}

To determine the growth at $10^{\circ} \mathrm{C}, 15^{\circ} \mathrm{C}$ and $45^{\circ} \mathrm{C}$ temperatures, the MRS broth media was prepared by adding bromecresol purple at a rate of $0.004 \%$. Bromecresol purple was used to determine the color change from purple to yellow, indicating lactic acid production and cell growth. Fifty microliters of overnight activated culture were transferred into the tubescontaining $5 \mathrm{ml}$ test media. After inoculation, they were incubated for 7 days at $10^{\circ} \mathrm{C}, 15^{\circ} \mathrm{C}$ and $45^{\circ} \mathrm{C}$ in duplicates. Cell growth at any of these temperatures was detected by the change in the color of the cultures, from purple to yellow.

\section{Growth at different $\mathrm{NaCl}$ Concentrations}

A 50 $\mu$ l of overnight activated culture was transferred into the tube containing $4.95 \mathrm{~g}$ of $\mathrm{NaCl}$ test media. The $\mathrm{NaCl}$ test media was prepared by adding $0.004 \%$ Bromcresol purple with required amount of $\mathrm{NaCl}$ in MRS broth media. Isolates were inoculated for testing growth at $2 \%, 4 \%$ and $6.5 \% \mathrm{NaCl}$ solutions. They were incubated for 7 days at $37^{\circ} \mathrm{C}$ in the incubator. Changing color from purple to yellow has considered as evidence for cell growth.

\section{Sugar fermentation test}

The sugar (carbohydrate) fermentation tests were performed by inoculating bacterial culture into individual tubes containing sugars and incubated at $37^{\circ} \mathrm{C}$ for 24 hours. Fourteen sugars e.g., glucose, lactose, sorbitol, salicin, trehalose, melibiose, sucrose, mannitol, melezitose, maltose, galactose, arabinose, raffinose and ribose were used for sugar fermentation test in this study. Firstly, 10\% solution of each sugar was prepared in distilled water, with a gentle heat to facilitate dissolving completely followed by filtering through 0.2 microfilters. The stock solution was prepared by using $0.004 \%$ bromocresol purple with $0.85 \% \mathrm{NaCl}$ and sterilized it by using autoclave at $121^{\circ} \mathrm{C}$ for 15 minutes. Fifty microlitres of overnight activated culture were transferred into test tube containing $4 \mathrm{ml}$ stock solution with $950 \mu \mathrm{l}$ specific sugar solution. At the same time sterilized Durham's tube was added inversely into the test tube to detect gas production. Acid production was indicated by the change of media color from purple to yellow while gas production was indicated by the appearance of gas bubbles in the inverted Durham's fermentation tubes.

\section{Results and Discussion}

Table 1 shows the results of LAB populations in different collected sample as expressed by colony-forming unit per millilitre of sample (cfu/ml). It was observed that MV yogurt sample showed higher LAB count $\left(9.5 \times 10^{5}\right.$ $\mathrm{cfu} / \mathrm{ml}$ ) and $\mathrm{Mw}$ yogurt sample showed lower number of LAB count $\left(1.0 \times 10^{4}\right.$ $\mathrm{cfu} / \mathrm{ml}$ ) among the samples. On the other hand, LAB was not observed in Nab, WF and $\mathrm{Kw}$ yogurt sample. Overall, lower concentrations of LAB was observed in all other collected samples. Hasan et al. (2016) observed standard plate count (SPC) in local Bogra yogurt sample was $3.47 \times 10^{7} \mathrm{cfu} / \mathrm{ml}$ while. Hossain et al., (2015) also reported that the range of SPC of different yogurt sample was $1.54 \times 10^{9}$ to $1.68 \times 10^{12} \mathrm{cfu} / \mathrm{ml}$. 
However, in those studies, nutrient agar was used for counting bacteria, while in this study MRS agar was used, which allowed only LAB to grow on media. Live viable bacterial counts may differ sample to sample depending on duration and mode of preservation while cocci shaped isolates were heterofermentative. Based on these results, the isolates found catalase-negative, Gram positive, rod shaped and homofermentative identified as genus Lactobacillus. This was in with agreement with Abdullah et al. (2010),

Table 1. Live viable count of LAB in collected yogurt samples

\begin{tabular}{l|c}
\hline Name of Yogurt samples & LAB count $(\mathrm{cfu} / \mathrm{ml})$ \\
\hline Bog & $3.8 \times 10^{5}$ \\
\hline MV & $9.5 \times 10^{5}$ \\
\hline PSt & $3.8 \times 10^{5}$ \\
\hline PSr & $4.0 \times 10^{4}$ \\
\hline Bik & $5.0 \times 10^{4}$ \\
\hline Mw & $1.0 \times 10^{4}$ \\
\hline Nab & n.d \\
\hline WF & n.d \\
\hline
\end{tabular}

n.d $=$ Not detected

(e.g., refrigeration) by the retailers, other artificial treatments (e.g., UV treatment) by the manufacturer to make bacteria weakened or killed. Table 2 shows the results of catalase test, Gram staining and gas production test. As there were no live viable bacteria found in the sample of $\mathrm{Nab}, \mathrm{Kw}$ and WF, they were not subjected for following tests regarding identification and characterization. A total of randomly selected 150 isolates from remaining 6 samples were considered for catalase test, Gram staining and gas production test. It was found that only 15 out of 150 isolates were lactic acid producing bacteria (LAB) according to the characteristics described by Sharpe (1979). Microscopic examination followed by Gram staining suggested that 7 isolates of $\mathrm{LAB}$ were rod shaped while the remaining 8 were cocci shaped bacteria. Further, gas production from glucose test revealed that all those rod shaped isolates were homofermentative,
Erkus (2007), Erdourul and Erbulur (2006). On the other hand, isolates found catalase-negative, Gram-positive, cocci shaped and heterofermentative were identified under the genus Leuconostoc, which was in similar with Azadnia et al. (2009).

The results of bacterial growth in different concentrations $(2,4$ and $6.5 \%)$ of $\mathrm{NaCl}$ and at different temperatures $\left(10,15\right.$ and $\left.45^{\circ} \mathrm{C}\right)$ are presented in Table 3. Results showed that total 4 isolates ( 1 of MV and Bog and 2 of PSr yogurt) out of 15 have grown in all three concentrations of $\mathrm{NaCl}$, and they also have grown at $45^{\circ} \mathrm{C}$, but not at 10 or $15^{\circ} \mathrm{C}$ indicating their thermophilic nature. In contrary, total 8 isolates (1 from each MV, Mw , Bik and Bog and 2 from each PSt and $\mathrm{PSr}$ ) did not grow in presence of $\mathrm{NaCl}$ in any of the concentrations tested, while these isolates grow at 10 and $15^{\circ} \mathrm{C}$, but not at $45^{\circ} \mathrm{C}$, indicating they are mesophilic. 
Table 2. Characterization of isolates based on catalase test, Gram staining, microscopic examination and gas production from Glucose.

\begin{tabular}{|c|c|c|c|c|c|c|c|c|c|c|c|c|c|c|c|}
\hline \multirow{2}{*}{$\begin{array}{l}\begin{array}{l}\text { Yogurt } \\
\text { name }\end{array} \\
\text { Isolates }\end{array}$} & \multicolumn{3}{|c|}{ MV } & \multirow{2}{*}{\begin{tabular}{|c|} 
Mw \\
1
\end{tabular}} & \multicolumn{3}{|c|}{ PSt } & \multicolumn{4}{|c|}{$\mathrm{PSr}$} & \multicolumn{2}{|c|}{ Bik } & \multicolumn{2}{|c|}{ Bog } \\
\hline & 1 & 2 & 3 & & 1 & 2 & 3 & 1 & 2 & 3 & 4 & 1 & 2 & 1 & 2 \\
\hline $\begin{array}{l}\text { Catalase } \\
\text { activity }\end{array}$ & - & - & - & - & - & - & - & - & - & - & - & - & - & - & - \\
\hline $\begin{array}{l}\text { Grams } \\
\text { stain } \\
\text { reaction }\end{array}$ & + & + & + & + & + & + & + & + & + & + & + & + & + & + & + \\
\hline Cell shape & Rod & Rod & Cocci & Cocci & Rod & Cocci & Cocci & Rod & Rod & Cocci & Cocci & Rod & Cocci & Rod & Cocci \\
\hline $\begin{array}{l}\text { Gas from } \\
\text { Glucose }\end{array}$ & - & - & + & + & - & + & + & - & - & + & + & - & + & - & + \\
\hline $\begin{array}{l}\text { Fermentati } \\
\text { on type }\end{array}$ & Homo & $\begin{array}{c}\text { Hom } \\
0\end{array}$ & $\begin{array}{c}\text { Heter } \\
0\end{array}$ & Hetero & $\begin{array}{c}\text { Hom } \\
0\end{array}$ & Hetero & Hetero & Homo & Homo & Hetero & Hetero & Homo & Hetero & Homo & Hetero \\
\hline Genus & 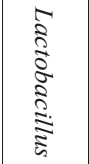 & 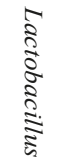 & $\begin{array}{c}\widehat{0} \\
\vdots \\
5 \\
0 \\
\vdots \\
0 \\
10\end{array}$ & 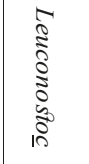 & 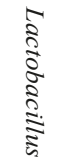 & $\begin{array}{l}\widehat{0} \\
\vdots \\
\vdots \\
0 \\
\vdots \\
0 \\
10\end{array}$ & 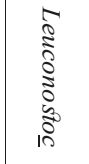 & 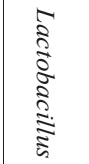 & 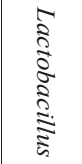 & 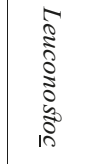 & 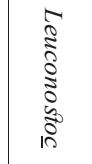 & $\begin{array}{l}5 \\
\vdots \\
0 \\
0 \\
\vdots \\
\vdots \\
\vdots \\
\vdots\end{array}$ & 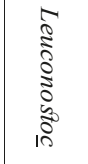 & 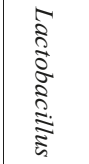 & 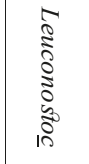 \\
\hline
\end{tabular}

Table 3. Growth of isolates found in different yogurt samples at different $\mathrm{NaCl}$ concentration and temperatures

\begin{tabular}{|c|c|c|c|c|c|c|c|c|c|c|c|c|c|c|c|}
\hline \multirow{2}{*}{$\begin{array}{l}\text { Yogurt name } \\
\text { Isolates }\end{array}$} & \multicolumn{3}{|c|}{ MV } & \multirow{2}{*}{$\begin{array}{c}\mathrm{Mw} \\
1\end{array}$} & \multicolumn{3}{|c|}{ PSt } & \multicolumn{4}{|c|}{$\mathrm{PSr}$} & \multicolumn{2}{|c|}{ Bik } & \multicolumn{2}{|c|}{ Bog } \\
\hline & 1 & 2 & 3 & & 1 & 2 & 3 & 1 & 2 & 3 & 4 & 1 & 2 & 1 & 2 \\
\hline \multicolumn{16}{|c|}{ Growth in different $\mathrm{NaCl}$ solution } \\
\hline $2 \% \mathrm{NaCI}$ & + & + & - & - & + & - & - & + & + & - & - & + & - & + & - \\
\hline $4 \% \mathrm{NaCI}$ & + & - & - & - & - & - & - & + & + & - & - & - & - & + & - \\
\hline $6.5 \% \mathrm{NaCI}$ & + & - & - & - & - & - & - & + & + & - & - & - & - & + & - \\
\hline \multicolumn{16}{|c|}{ Growth at different temperature } \\
\hline at $10^{\circ} \mathrm{C}$ & - & - & + & + & - & + & + & - & - & + & + & - & + & - & + \\
\hline at $15^{\circ} \mathrm{C}$ & - & - & + & + & - & + & + & - & - & + & + & - & + & - & + \\
\hline at $45^{\circ} \mathrm{C}$ & + & + & - & - & + & - & - & + & + & - & - & + & - & + & - \\
\hline
\end{tabular}

On the other hand, 3 remaining isolates (1 from each MV, PSt and Bik) out of 15 were also found thermophilic in nature as they did grow at $45^{\circ} \mathrm{C}$ and only in $2 \%$, but not in 4 and $6.5 \% \mathrm{NaCl}$ solution. The present results regarding heat tolerance characteristics of isolates can be explained with many other previous findings (Ammor et al., 2005; Guessas et al., 2004;
Hemme et al.,2004; Busson et al., 1999; Samelis et al., 1994).

Table 4 shows the sugar fermentation characteristics of isolates found in different yogurt samples. In this study, sugar fermentation tests included 14 sugars, which were, lactose, sorbitol, salicin, trehalose, melibiose, sucrose, 
mannitol, melezitose, maltose, galactose, glucose, arabinose, raffinose and ribose. Total 8 isolates (1 from each MV, Mw, Bik and Bog, 2 from each PSt and PSr) were observed to ferment only glucose and galactose among 14 sugar tested. These findings, in combinations with the results from Table 2 and 3 indicated that the isolate was Leuconostoc cremorisas also stated by Azadnia and Khan Nazer (2009).The Leuconostocs are Gram-positive cocci, occurring in pairs and chains, and form D (-) lactic acid and carbon dioxide from the fermentation of glucose indicating heterofermentative-type metabolism (Azadnia and Khan Nazer, 2009). The L. cremoris is biochemically differentiated by its inability to ferment trehalose and sucrose but it ferments glucose, galactose, and lactose (Azadnia and Khan Nazer, 2009).

A total of 3 isolates (1 from each MV, PSr and Bog) were found to able ferment lactose, salicin, trehalose, maltose and glucose. These characteristics, in combination with other biochemical properties as presented in Table 2 and Table 3 indicated that the isolate is Lcatobacillus lactisin accordance with (Abdullah et al., 2010) and Erkus (2007). The L. Lactis is catalase negative, Gram positive, rod shaped, thermophilic bacteria (grows at $45^{\circ} \mathrm{C}$ ), which form gas from glucose and can grow in 2 , 4 and $6.5 \% \mathrm{NaCl}$ solution (Erkus, 2007). These bacteria ferment lactose, salicin, trehalose, maltose and glucose but unable to ferment sorbitol, melibiose, melibiose, sucrose, mannitol, galactose, arabinose, ribose and raffinose (Erkus, 2007).

Two other isolates (1 from each MV and Bik) did ferment only glucose and lactose among the 14 sugars tested and the characteristics are inconsistent with Lactobacillus bulgaricus as described by (Abdullah et al., 2010) and Erkus

(2007). This species was described as catalase negative, Gram positive, rod shaped and had the ability to form gas from glucose. It is a thermophilic bacteria (grows at $45^{\circ} \mathrm{C}$ ), which can grow in $2 \% \mathrm{NaCl}$ but not in 4 and $6.5 \% \mathrm{NaCl}$. The L. bulgaricus ferments lactose and glucose but not salicin, trehalose, sucrose, maltose, sorbitol, melizitose, mellibiose, arabinose, ribose, raffinose, galactose and mannitol (Mithun et al, 2015; Erkus, 2007).

One isolate from PSt sample was identified as Lactobacillus acidophilus as it was found to ferment lactose, salicin, trehalose, sucrose, maltose and glucose but were unable to ferment sorbitol, melibiose, mannitol, melezitose, arabinose, raffinose and ribose. These sugar fermentation characteristics of L.acidophilus are in agreement with Mithun et al., 2015), Abdullah et al., 2010 and Erkus (2007). The L. acidophilus was characterized as catalase negative, Gram positive, rod shaped and had the ability to form gas from glucose (Heterofermentative), thermophilic in nature (grows at $45^{\circ} \mathrm{C}$ ), which can grow in $2 \% \mathrm{NaCl}$ but not in 4 and $6.5 \% \mathrm{NaCl}$ (Mithun et al, 2015; Erkus, 2007).

One isolate from PSr was found to ferment lactose, sorbitol, salicin, trehalose, sucrose, mannitol, melizitose, maltose, glucose and galactose, but not the mellibiose, arabinose, raffinose and ribose and can be identified as Lctobacillus helveticus according to Erkus (2007). The L. helveticus is catalase negative, Gram positive, rod shaped and produce gas from glucose (heterofermentative). It grows in 2, 4 and $6.5 \% \mathrm{NaCl}$ solution. It also grows at $45^{\circ} \mathrm{C}$ but not at $10^{\circ} \mathrm{C}$ and $15^{\circ} \mathrm{C}$ (Mithun et al, 2015; Erkus, 2007). 
Table 4. Carbohydrate fermentation characteristics of isolates obtained from different yogurt samples

\begin{tabular}{|c|c|c|c|c|c|c|c|c|c|c|c|c|c|c|c|}
\hline Sample ID & \multicolumn{3}{|c|}{ MV } & $\mathrm{Mw}$ & \multicolumn{3}{|c|}{ PSt } & \multicolumn{4}{|c|}{$\mathrm{PSr}$} & \multicolumn{2}{|c|}{ Bik } & \multicolumn{2}{|c|}{ Bog } \\
\hline Isolates & 1 & 2 & 3 & 1 & 1 & 2 & 3 & 1 & 2 & 3 & 4 & 1 & 2 & 1 & 2 \\
\hline Lactose & + & + & - & - & + & - & - & + & + & - & - & - & - & + & - \\
\hline Sorbitol & - & - & - & - & - & - & - & - & + & - & - & - & - & - & - \\
\hline Salicin & + & - & - & - & + & - & - & + & + & - & - & - & - & + & - \\
\hline Trehalose & + & - & - & - & + & - & - & + & + & - & - & - & - & + & - \\
\hline Mellibiose & - & - & - & - & - & - & - & - & - & - & - & - & - & - & - \\
\hline Sucrose & - & - & - & - & + & - & - & - & + & - & - & - & - & - & - \\
\hline Manitol & - & - & - & - & - & - & - & - & + & - & - & - & - & - & - \\
\hline Melezitose & - & - & - & - & - & - & - & - & + & - & - & - & - & - & - \\
\hline Maltose & + & - & - & - & + & - & - & + & + & - & - & - & - & + & - \\
\hline Galactose & - & - & + & + & - & + & + & - & + & + & + & - & + & - & + \\
\hline Glucose & + & + & + & + & + & + & + & + & + & + & + & + & + & + & + \\
\hline Arabinose & - & - & - & - & - & - & - & - & - & - & - & - & - & - & - \\
\hline Raffinose & - & - & - & - & - & - & - & - & - & - & - & - & - & - & - \\
\hline Ribose & - & - & - & - & - & - & - & - & - & - & - & - & - & - & - \\
\hline Species & 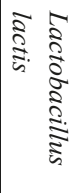 & 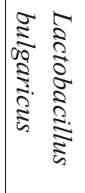 & 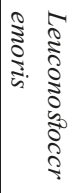 & 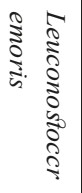 & 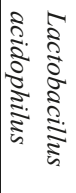 & 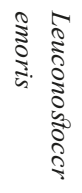 & 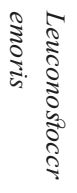 & 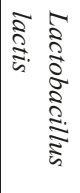 & 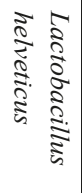 & 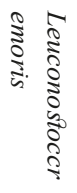 & 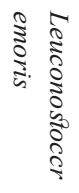 & 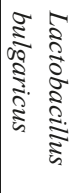 & 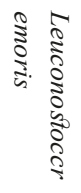 & 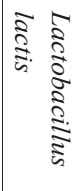 & 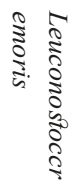 \\
\hline
\end{tabular}

\section{Conclusion}

In can be concluded that total of five different species of LAB were identified from six local yogurt samples. The isolate Lactobacillus lactis was identified in MV, $\mathrm{PSr}$ and Bog yogurt, while Lactobacillus bulgaricus was found in $\mathrm{MV}$ and Bik sample. The species Leuconostoc cremoris, a flavor producing bacteria in yogurt, was found in all six yogurt samples containing live viable colonies. On the other hand Lactobacillus acidophilus and Lactobacillus helveticus was found only in PSt and PSr yogurt samples.

\section{References}

Abdullah, S.A. and Osman, M.M. 2010. Isolation and identification of lactic acid bacteria from raw cow milk, white cheese and rob in Sudan. Pak. J. Nutri. 9 (12): 1203-1206.

Ali, M.Y., Islam, M.A., Alam, M.J. and Islam M.N. 2002.Quality of yoghurt (Dahi) prepared in laboratory and available in the market of Mymensing town in Bangladesh, Pak. J. Biol. Science. 5(3): 343-345.

Ammor, S., Rachman, C., Chaillou, S., Prévost, H., Dousset, X., Zagorec, M., Dufour, E. and Chevallier. 2005. Phenotypic and genotypic identification 
of lactic acid bacteria isolated from a small-scale facility producing traditional dry sausages. Food Microbiol. 22: 373-382.

Azadnia, P. and Khan Nazer, A.H. 2009. Identification of lactic acid bacteria isolated from traditional drinking yoghurt in tribes of Fars province. Iranian J. Vet. Res. 10(3): 235-240.

Azadnia, P. and Khan Nazer, A.H. 2009. Identification of lactic acid bacteria isolated from traditional drinking yoghurt in tribes of Fars province, Iranian Journal of Veterinary Research. 10(3): 235-240.

Busson, C.S., Foucaud, C. and Leveau, J.Y. 1999. Selection of dairy Leuconostoc isolates for important technological properties. J. Dairy Res. 66: 245-256.

Erdourul, Z. and Erbulur, F. 2006. Isolation and characterization of lactobacillus bulgaricus and lactobacillus casei from various foods. Turk J Biol.30 (39-44).

Erkuş, O. 2007.Isolation, phenotypic and genotypic characterization of yoghurt starter bacteria.MS thesis.Izmir Institute of technology, Izmir, Turkey.

Guessas, B. and Kihal, M. 2004. Characterization of lactic acid bacteria isolated from Algerian arid zone raw goats' milk. Afr. J. Biotechnol. 3: 339-342.

Hasan, G.A., Parveen, S., Sultana, J. 2016. Microbiological quality analysis of aw milk and yogurt available in some selected areas of Bangladesh. Int. J. Inno. Res. Sci., Eng. and Tech. 5(3):2855-2859.
Hemme, D. and Foucaud-Scheunemann, C. 2004.Leuconostoc, characteristics, use in dairy technology and prospects in functional foods. Int. Dairy J. 14: 467-494.

Hossain, A.Z., Shaheb, M.R., Ahmed, S. and Sarker, A. 2015. Studies on the microbial quality of yoghurts in Sylhet city and preparation of new flavoured yoghurts. American J. food sci. nut. res. 2(6): 172-179.

Hui, Y.H. 1992. In: Dairy Science and Technology Handbook, 2 product Manufacturing. pp. 13-14.

Mithun, S., Dipak, V. and Sheela, S. 2015. Isolation and identification of lactobacilli from raw milk samples obtained from Aarey Milk Colony. Int. J. Sci. Res. Pub., Volume 5:4

Reiner, K. 2010. Catalase Test Protocol. American Society for Microbiology. pp. 1-9.

Samelis, J., Maurogenakis, F. and Metaxopoulos, J. 1994. Characterization of lactic acid bacteria isolated from naturally fermented Greek dry salami. Int. J. Food Microbiol. 23: 179-196.

Sharpe, M.E. 1979. The genus Lactobacillus. In: The prokaryotes: A hand book on Habitats, Isolation and Identification of Bacteria, Edited by-Starrs, M.P., Stolp, H., Balows, A. \& Schlegel, H., Springer-Verlag Berlin Heidelberg, New York city, pp.1653-1679. 